\title{
TUBERCULOSIS AND DIABETES MELLITUS- NOT A SWEET ASSOCIATION!
}

\author{
Amitabh Das Shukla1, Abhinav Chaudhary², A. Shreenivasa ${ }^{3}$ \\ ${ }^{1}$ Associate Professor, Department of Pulmonary Medicine, Moti Lal Nehru Medical College. \\ ${ }^{2} 3^{\text {rd }}$ Year Junior Resident, Department of Pulmonary Medicine, Moti Lal Nehru Medical College. \\ ${ }^{3} 3^{\text {rd }}$ Year Junior Resident, Department of Pulmonary Medicine, Moti Lal Nehru Medical College.
}

\section{ABSTRACT}

\section{BACKGROUND}

Tuberculosis (TB) continues to be the leading killer among bacterial diseases worldwide. Diabetes is making people three times more susceptible to get active tuberculosis infection. Diabetes Mellitus (DM) is quietly fuelling the spread of tuberculosis. The association between diabetes and TB may be the next challenge for global tuberculosis control worldwide.

This study aims to find out proportion of DM among pulmonary tuberculosis patients and proportion of DM among patients with different sputum bacillary load.

\section{MATERIALS AND METHODS}

An observational cross-sectional study was conducted at MLN Medical College, Allahabad. A total of 1691 presumptive TB cases aged $\geq 18$ years were enrolled, out of them 257 sputum smear positive pulmonary TB cases were included in the study. Data were collected using a structured questionnaire to elicit demographic and clinical variables including a history of diabetes. An HbA1c value of $6.5 \%$ or above was considered diagnostic of DM. Data was analysed on Microsoft Office Excel worksheet.

\section{RESULTS}

Out of total 1691 presumptive TB cases enrolled, 257 were diagnosed as sputum smear positive pulmonary TB cases. Both TB and DM were more common among males. Proportion of DM among sputum positive pulmonary TB patients was $7.39 \%$. Proportion of DM is $8.33 \%$ among patients with bacillary load 3+ and 7.04\% among patients with bacillary load 1+. Proportion of DM increases in pulmonary TB patients with older age. DM proportion was $3.7 \%$ among patients age < 40 years, while proportion was $14.2 \%$ among patients age $>60$ years $(\mathrm{p}$-value $=0.012)$.

\section{CONCLUSION}

In conclusion, this study shows a high proportion of DM among males, patients with active TB, older age group and in patients with high sputum bacillary load. An improved understanding of the bidirectional relationship of the two diseases is necessary for proper planning and collaboration to reduce the dual burden of diabetes and TB. We should increase public awareness about the risk factors or association of TB and DM together.

\section{KEYWORDS}

Tuberculosis, Diabetes Mellitus.

HOW TO CITE THIS ARTICLE: Shukla AD, Chaudhary A, Shreenivasa A. Tuberculosis and diabetes mellitus- not a sweet association! J. Evolution Med. Dent. Sci. 2017;6(62):4518-4521, DOI: 10.14260/Jemds/2017/977

\section{BACKGROUND}

Tuberculosis (TB) continues to be the leading killer among bacterial diseases worldwide. In 2015, there were an estimated 10.4 million new (incident) TB cases worldwide and 1.7 million people died from the disease.[1] India accounts for around $27 \%$ of the world's TB cases. ${ }^{[1]}$

Diabetes Mellitus (DM) is a chronic, non-communicable disease that weakens the immune system, making people with diabetes 3 times more likely to get active TB as compared to non-diabetics.[2] Diabetes is no longer a disease of predominantly rich nations; its prevalence has been rising more rapidly in middle and low-income countries.[3] The number of DM patients increased from 108 million in 1980 to

Financial or Other, Competing Interest: None.

Submission 28-06-2017, Peer Review 20-07-2017,

Acceptance 27-07-2017, Published 03-08-2017.

Corresponding Author:

Dr. Amitabh Das Shukla,

Associate Professor,

Department of Pulmonary Medicine,

Moti Lal Nehru Medical College.

E-mail: adshukla1977@gmail.com

DOI: $10.14260 /$ jemds $/ 2017 / 977$ 422 million in 2014. India had 69.2 million people living with diabetes $(8.7 \%)$ as per the 2015 data. Of these, it remained undiagnosed in more than 36 million people. ${ }^{[4]}$

Richard Morton in his Phthisiologia stated that TB and DM association has been known since Roman times.[5] Susruta also described relation of TB and DM and Avicenna in his Canon of Medicine stated that 'phthisis' is often complicated by DM.[6]

These two diseases are world's leading causes of death and disability. Diabetes mellitus is quietly fuelling the spread of tuberculosis. The association between diabetes and TB may be the next challenge for global tuberculosis control worldwide. A good planning, collaboration and implementation are necessary to reduce the dual burden of DM and TB. This study aims to finds out proportion of DM among pulmonary tuberculosis patients and proportion of DM among patients with different sputum bacillary load.

\section{MATERIALS AND METHODS}

The present study comprised of patients attending the Department of Pulmonary Medicine, MLN Medical College, Allahabad, during the period from January 2017 to June 2017. 


\section{Study Design}

This was an observational cross-sectional study assessing proportion of Diabetes Mellitus among pulmonary tuberculosis cases.

\section{Study Sample}

Total 1691 patients (inpatients and outpatients) of presumptive TB cases attending Department of Pulmonary Medicine, MLN Medical College, Allahabad, were registered during the course of the study. Sputum smear microscopy is performed in all presumptive TB cases.

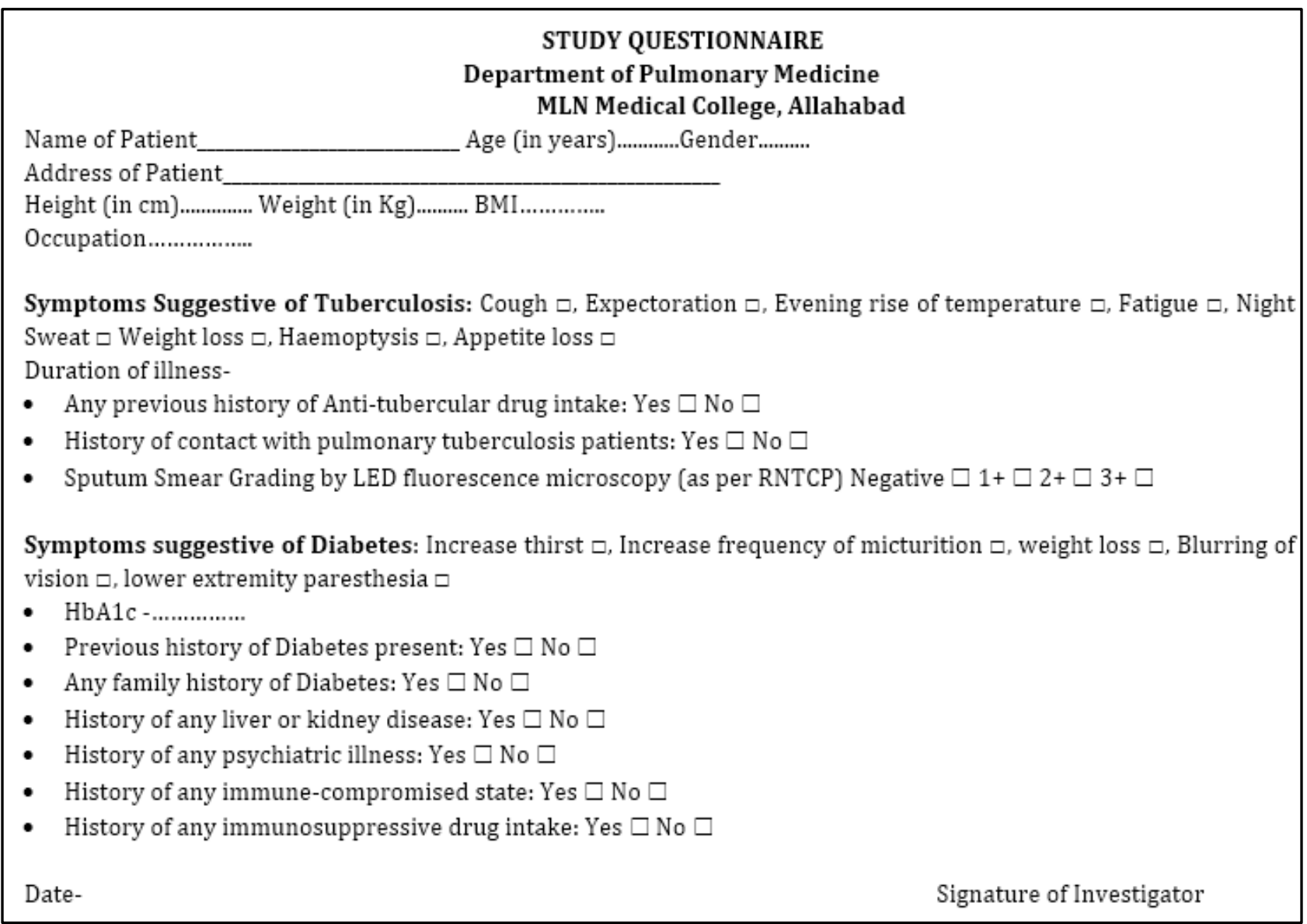

\section{Case Selection}

All patients aged $>18$ years of either sex with presumptive TB cases were enrolled in this study as per inclusion and exclusion criteria. Out of 1691 presumptive TB cases; 257 were diagnosed as sputum smear positive pulmonary TB cases and were included in the study.

\section{Inclusion Criteria}

1. Patients with sign and symptom suggestive of tuberculosis.

\section{Exclusion Criteria}

1. Patient not giving consent for participation in the study.

2. Pregnant women.

3. Patient with co-morbid illness like AIDS, liver disease and psychiatric illness.

\section{Data Collection and Analysis}

Data were collected using a structured questionnaire to elicit demographic and clinical variables including history of diabetes and analysed on Microsoft Office Excel worksheet. For patients consenting to DM screening, blood samples were collected and glycosylated haemoglobin (HbA1c) levels were measured from whole blood. An HbA1c value of $6.5 \%$ or above was considered diagnostic of DM, in line with recommendations of American Diabetes Association.[7] For patients with self-reported DM, a glycosylated haemoglobin (HbA1c) level 7\% was taken to indicate poorly controlled disease.

\section{Investigations}

1. Routine haematological (Hb, TLC, DLC, ESR, GBP), liver function test and kidney function test.

2. HbA1c.

3. Bacteriological examination (sputum smear examination for M. tuberculosis by LED fluorescence microscope).

4. Chest radiograph postero-anterior view.

Sputum Smear Fluorescence Microscopy Grading (As per RNTCP)

\begin{tabular}{|c|c|}
\hline $\begin{array}{c}\text { Auramine O Fluorescent Staining } \\
\text { Grading (Using }\end{array}$ & $\begin{array}{c}\text { Reporting } \\
\text { /Grading }\end{array}$ \\
\hline $\begin{array}{c}\text { 20 or 25x Objective and 10x Eye Piece) } \\
\text { examination of } 20 \text { fields }\end{array}$ & Positive, 3+ \\
\hline $\begin{array}{c}11-100 \mathrm{AFB} / \text { field after } \\
\text { examination of } 50 \text { fields }\end{array}$ & Positive, $2+$ \\
\hline $\begin{array}{c}1-10 \mathrm{AFB} / \text { field after examination of } 100 \\
\text { fields }\end{array}$ & Positive, $1+$ \\
\hline
\end{tabular}




\section{RESULTS}

A total of 1691 presumptive TB cases were enrolled in this study, but only 257 were having sputum smear positive pulmonary tuberculosis. Out of 257 sputum smear positive patients, TB was more common among males $(n=179)$ than female $(n=78)$ and DM is also common among males $(n=15)$ than females $(n=4)$.

Proportion of DM among sputum positive pulmonary TB patients (7.39\%) was significantly more than sputum negative suspects [Table 1].

\begin{tabular}{|c|c|c|}
\hline $\begin{array}{c}\text { Sputum AFB Smear Stain of } \\
\text { Presumptive TB Cases } \\
(\mathrm{n}=\mathbf{1 6 9 1})\end{array}$ & DM & Non-DM \\
\hline Positive (n= 257) & $19(7.39 \%)$ & 238 \\
\hline Negative (n= 1434) & $51(3.55 \%)$ & 1383 \\
\hline Table 1. Proportion of DM among Pulmonary \\
Tuberculosis Patients \\
\hline
\end{tabular}

$(\mathrm{P}-\mathrm{value}=0.0095)$

Although DM was found associated with greater bacillary load among sputum smear positive pulmonary tuberculosis patients, this difference was not statistically significant. Proportion of DM is $8.33 \%$ among patients with bacillary load $3+$ and $7.04 \%$ among patients with bacillary load 1+ [Table 2].

\begin{tabular}{|c|c|c|}
\hline Sputum Bacillary Load & DM & Non-DM \\
\hline $1+(\mathrm{n}=142)$ & $10(7.04 \%)$ & 132 \\
\hline $2+(\mathrm{n}=43)$ & $3(6.97 \%)$ & 40 \\
\hline $3+(\mathrm{n}=72)$ & $6(8.33 \%)$ & 66 \\
\hline \multicolumn{3}{|c|}{ Table 2. Proportion of DM among Patients with } \\
\hline
\end{tabular}

$(\mathrm{P}-$ value $=0.93)$

Among all sputum AFB smear positive pulmonary tuberculosis patients, proportion of DM is higher among patients with older age group. DM proportion was 3.7\% among patients aged $<40$ years, while proportion was $14.2 \%$ among patients aged $>60$ years [Table 3 ].

\begin{tabular}{|c|c|c|}
\hline Age Group & DM & Non-DM \\
\hline 18-40 years (n= 162) & $6(3.7 \%)$ & 156 \\
\hline 40-60 years (n= 67) & $9(13.4 \%)$ & 58 \\
\hline > 60 years (n= 28) & $4(14.2 \%)$ & 24 \\
\hline \multicolumn{2}{|c|}{ Table 3. Proportion of DM in different Age Group of } \\
Pulmonary TB Patients \\
\hline
\end{tabular}

$(\mathrm{P}$-value $=0.012)$

\section{DISCUSSION}

There are various factors which attribute for high association of diabetes with TB like low opsonic index, decreased bactericidal activity, decreased synthesis of collagen, impaired defensive function of reticuloendothelial cell, increased availability of glycerol in tissue that act as substrate for growth of Mycobacterium tuberculosis bacilli, lack of adequate substrate for antibody formation due to disturbed protein metabolism and lowered production of IL-1 beta and TNF alpha by peripheral blood monocytes.
Proportion of DM among Pulmonary Tuberculosis Patients

This study shows proportion of DM among pulmonary TB patients was $7.39 \%$.

However, the prevalence of DM among TB patients ranged from $1.9 \%$ in Cotonou-Benin to $45 \%$ in EbeyeMarshall Islands. ${ }^{[8,9]}$ Workneh $\mathrm{MH}$ et al systemic review shows an overall global median DM prevalence of $16 \%$ (IQR $9.0-25.3 \%) .[10]$

\section{Proportion of DM among Patients with different Bacillary Load}

This study shows proportion of DM was higher among patients with high bacillary load. Matthew J Magee et al shows that patients with TB and DM were more likely to have a higher AFB smear grade (aOR 2.37, 95\% CI 1.14 - 4.94).[11]

Dooley, Kelly E et al shows higher sputum positivity in patients with DM.[12]

Park SW et al shows a higher positive smear rates $(\mathrm{p}<0.001)$ among diabetics as compared with nondiabetics.[13]

\section{Proportion of DM in different Age Groups of Pulmonary TB Patients}

This study shows that proportion of patients with DM is high among older age groups. Zheng $\mathrm{C}$ et al[14] shows that median age of patients with TB-DM is $49.5+-11.8$, p-value $=0.001$. Wang $Q$ et al[15] also shows high proportion of DM as age increases.

\section{CONCLUSION}

In conclusion, this study shows a high proportion of DM among male patients with active TB, older age group and high sputum bacillary load. Diabetes mellitus is fuelling the spread of tuberculosis. So, an improved understanding of the bidirectional relationship of the two diseases is necessary for proper planning and collaboration to reduce the dual burden of diabetes and TB. We should increase public awareness about the risk factors or association of TB and DM together.

\section{REFERENCES}

[1] Global TB report. World Health Organization, Geneva, 2016.

[2] Jeon CY, Murray MB. Diabetes mellitus increases the risk of active tuberculosis: a systematic review of 13 observational studies. PLoS Med 2008;5(7):e152.

[3] Global report on diabetes. World Health Organization, Geneva, 2016.

[4] World Health Day 2016: Diabetes http://www.searo.who.int/india/mediacentre/events /2016/en/

[5] Morton R. Phthisiolgia: or a treatise of consumptions. London: Smith and Walford, 1694.

[6] Barach JH. Historical facts in diabetes. Annals of Medical History 1928;10:387-401.

[7] American Diabetes Association. Standards of medical care in diabetes. Diabetes Care 2017;40(Suppl 1):S1124. 
[8] Ade S, Affolabi D, Agodokpessi G, et al. Low prevalence of diabetes mellitus in patients with tuberculosis in Cotonou, Benin. Public Health Action 2015;5(2): 147-9.

[9] Nasa JN, Brostrom R, Ram S, et al. Screening adult tuberculosis patients for diabetes mellitus in Ebeye, republic of the Marshall Islands. Public Health Action 2014;4(Suppl 1):S50-2.

[10] Workneh MH, Bjune GA, Yimer SA. Prevalence and associated factors of tuberculosis and diabetes mellitus comorbidity: a systematic review. PLoS ONE 2017;12(4):e0175925.

[11] Magee MJ, Kempker RR, Kipiani M, et al. Diabetes mellitus is associated with cavities, smear grade, and multidrug resistant tuberculosis in Georgia. Int J Tuberc Lung Dis 2015;19(6):685-92.
[12] Dooley KE, Tang T, Golub JE, et al. Impact of diabetes mellitus on treatment outcomes of patients with active tuberculosis. The American Journal Of Tropical Medicine And Hygiene 2009;80(4):634-9.

[13] Park SW, Shin JW, Kim JY, et al. The effect of diabetic control status on the clinical features of pulmonary tuberculosis. Eur J Clin Microbiol Infect Dis 2012;31(7):1305-10.

[14] Zheng C, Hu M, Gao F. Diabetes and pulmonary tuberculosis: a global overview with special focus on the situation in Asian countries with high TB-DM burden. Global Health Action 2017;10(1):1-11.

[15] Wang Q, Ma A, Han X, et al. Prevalence of type 2 diabetes among newly detected pulmonary tuberculosis patients in China: a community based cohort study. PLoS ONE 2013;8(12):e82660. 